\title{
Borrelia burgdorferi antibodies in patients with relapsing/remitting form and chronic progressive form of multiple sclerosis
}

\author{
ERICH SCHMUTZHARD, PETER POHL, GEROLD STANEK* \\ From the Department of Neurology, University Hospital, Innsbruck, and the Hygiene Institute, ${ }^{*}$ University of \\ Vienna, Austria
}

SUMMARY Sera of 106 multiple sclerosis patients and 103 closely matched controls were examined for Borrelia burgdorferi antibodies. The prevalence rate in multiple sclerosis patients was $14 \cdot 2 \%$, in controls $25 \cdot 2 \%$. Overall prevalence was $20 \cdot 1 \%$. Mean IgG antibody level was insignificantly higher in controls than in multiple sclerosis patients. Patients with a chronic progressive course of multiple sclerosis had an insignificantly higher mean borrelia antibody level, when compared with those suffering from relapsing/remitting form of disease.

In the past few years there have been numerous reports of central nervous system (CNS) manifestations of third stage Lyme borreliosis (LB), extending the neurological spectrum. ${ }^{1}$ Neuropsychiatric manifestations resembling general paresis in third stage syphilis have been delineated by Pachner and Steere as well as focal CNS lesions appearing months or years after the initial infection. ${ }^{2}$ Already in 1985 Ackermann et al coined the term "Progressive Borrelia Encephalomyelitis"3 indicating a chronic third stage borrelial infection of the brain ${ }^{3-5}$ and spinal cord ${ }^{367}$ sometimes showing a remitting, sometimes a progressive course of disease.$^{36-14}$ In a few instances the disease seemed to be indistinguishable from multiple sclerosis. ${ }^{91516}$ In this respect conflicting results have been presented by several authors. ${ }^{9151718}$ Controversy has been accentuated by Gay and Dick's hypothesis of a possible spirochetal origin of multiple sclerosis. ${ }^{171920}$ It seems to be beyond doubt that CNS involvement does occur in third stage LB, ${ }^{236811-1418}$ its course sometimes imitating a multiple sclerosis-like disease. Moreover, Kristoferitsch et al showed oligoclonal banding in

Address for reprint requests: Dr E Schmutzhard, Department of Neurology, University Hospital, Anichstraße 35, A-6020 Innsbruck, Austria.

Received 6 October 1987 and in final revised form 15 March 1988. Accepted 2 April 1988 cerebrospinal fluid in neuroborreliosis, ${ }^{21}$ a widely used and important criterion for diagnosing multiple sclerosis. $^{223}$

However, in view of the high prevalence of $B$. burgdorferi antibodies in many parts of Europe ${ }^{24-26}$ and the low expression of disease in cases of infective tick bite, it appears likely that multiple sclerosis patients have borrelia antibodies although $B$. burgdorferi is not the causative agent of the disease.

In order to obtain relevant epidemiological information about this problem we have undertaken a serological survey of multiple sclerosis patients and compared the data with closely matched controls having the same geographical and ecological background.

\section{Patients and methods}

The records of the Department of Neurology at the University Hospital Innsbruck list 239 patients with the diagnosis of probable or definite multiple sclerosis. In addition to the criteria for diagnosing multiple sclerosis given by Rose $^{22}$ and Poser, ${ }^{23}$ confirmatory magnetic resonance imaging has been performed in most patients for the past $2 \frac{1}{2}$ years.

Only patients originating from the province of Tyrol were eligible. Fifty-seven patients had died, were not residents of, or had moved away from our province, 42 refused to take part in the study. Twenty-seven could not be traced for a variety of reasons. In seven instances the sera were lost, thus a remaining 106 patients could be included in this study. All patients and control persons were visited at home. As a 
control, usually a close family member, living in the same household, or within the vicinity, was chosen. For three patients, living in an institution for aged people no controls were available; thus their number was 103 .

The patients and controls had to fill out a short questionnaire dealing with their disease, living habits, previous tickbites and therapy. From all persons $10 \mathrm{ml}$ blood was drawn for serological examination. This was done at the Hygiene Institute of the University of Vienna, by means of ELISA technique.

The ELISA test was performed as described elsewhere. ${ }^{27}$ Briefly, sonicated B. burgdorferi B31 at a concentration of $10 \mu \mathrm{g} / \mathrm{ml}$ was coated onto Nunc microtitre plates by overnight incubation in a pH 9.6 carbonate buffer. Subsequent incubations were performed with human sera, peroxidaseconjugated goat anti-human antibody, and substrate, with washes between the incubation. Colour was read by SLT 210.6 photometer at a wavelength of $495 \mathrm{~nm}$. The results underwent a computer assisted analysis and were expressed as numerical units. Results were considered as positive when units were calculated $\geq 4.5$ at a cut off at $0.2 \mathrm{~nm}$.

For statistical analysis Student's $t$ test and chi square test were applied.

\section{Results}

Median age of multiple sclerosis patients was 45 years (range 18-74), of controls 41 years (range 14-79); there were 72 female and 34 male patients, versus 57 female and 46 male controls. Fifteen out of 106 multiple sclerosis patients $(14.2 \%)$ and 26 of 103 controls $(25 \cdot 2 \%)$ had IgG borrelia antibodies above the chosen threshold level in their serum (fig 1). Mean IgG B antibody level of multiple sclerosis patients and controls was 3.48 SD 0.9 ELISA Units (EU) (that is a reciprocal relative ELISA titre of 500), and 3.75 SD

1.1 EU (reciprocal relative ELISA titre 675)

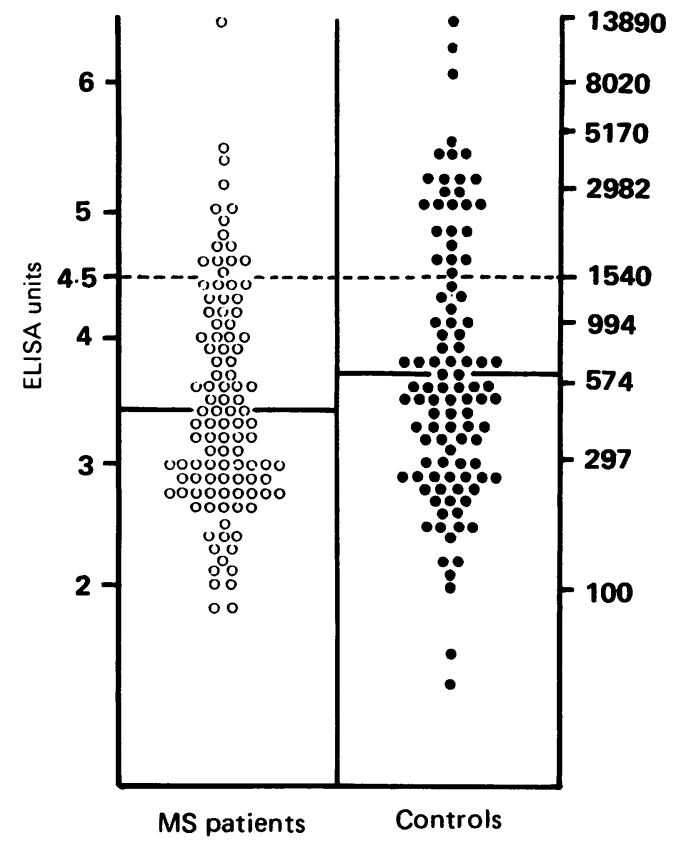

Fig 1 Borrelia IgG antibody levels in serum of 106 multiple sclerosis patients and 103 closely matched controls. A level of 4.5 ELISA Units (= reciprocal relative ELISA-titre of 1540) was used as upper limit of normal values.

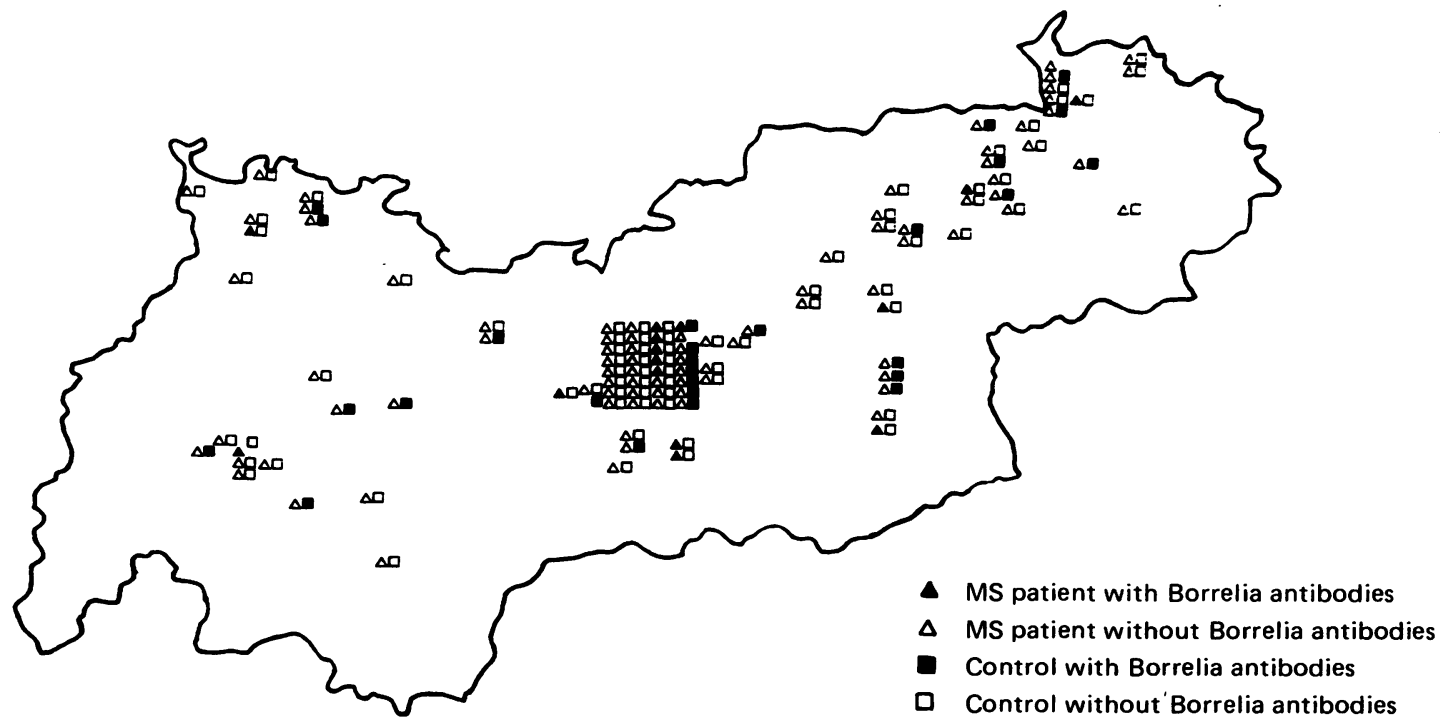

Fig 2 Map of province of Tyrol. Geographical distribution of multiple sclerosis patients and controls. 
respectively. Mean IgM antibody level was 2.7 SD 0.8 EU (reciprocal relative ELISA titre 214) in multiple sclerosis patients and 2.65 SD 0.6 EU (reciprocal relative ELISA titre 200) in controls. using Student's $t$ test no significant difference could be found between multiple sclerosis patients' and controls' antibody levels (IgG and IgM). Twenty nine patients (27.4\%) were suffering from a chronic progressive course of disease, whereas $67(63.2 \%)$ had a relapsing/remitting form of multiple sclerosis. In 10 patients $(9.4 \%)$ classification was not possible. Mean borrelia antibody level (IgG) in chronic progressive patients was 3.7 SD 1.3 EU. Their controls had a mean of 3.8 SD 1.0 EU. In patients with relapsing/remitting multiple sclerosis a mean of 3.4 SD $0.9 \mathrm{EU}$ was found and a mean of 3.7 SD 1.0 EU in their corresponding controls. Comparing the titres of patients (both chronic progressive and relapsing/remitting) with their corresponding controls and titres of chronic progressive patients with those of relapsing/remitting patients, no significant difference could be found.

Median duration of illness was 10 years, range $<1$ year to 43 years. Positive correlation could neither be found between duration of illness and borrelia antibody titre $(r=0.19)$ nor between age and antibody titre $(r=0.21)$.

Twenty eight $(=26 \cdot 4 \%)$ multiple sclerosis patients and $32(=31 \cdot 1 \%)$ controls remembered a tick bite; no difference, however, could be found between the antibody level of the tick bite positive and negative persons $(\bar{X}=3.57$, SD 1.24 versus $\bar{X}=3.64$, SD 0.92 EU). Of those with antibody level above threshold (>4.5 EU) $3 / 15$ multiple sclerosis patients and $9 / 27$ controls had a history of tick bite.

Fifty seven multiple sclerosis patients $(53.8 \%)$ but 75 controls $(72 \cdot 8 \%)$ reported frequent visits to forests and woods (chi square $=4.69 ; \alpha<0.05$ ).

The geographical distribution of all patients and controls is shown in fig 2 . There is no regional preference or predominance of $B$. burgdorferi antibodypositive persons. The overall $B$. burgdorferi antibody prevalence was $20 \cdot 1 \%$.

\section{Discussion}

Third stage Lyme borreliosis can involve the CNS, sometimes imitating a multiple sclerosis-like course. ${ }^{612131516}$ The aetiology of multiple sclerosis is still controversial; lately spirochetes have been incriminated ${ }^{1920}$ and even borreliae are discussed. ${ }^{15}$

In our study the mean IgG borrelia antibody level was slightly higher in control persons than in multiple sclerosis patients, although not significantly. Patients suffering from a chronic progressive course of multiple sclerosis had higher (not significantly, $p<0 \cdot 1$ )
IgG B. antibodies than those with remitting/relapsing form of multiple sclerosis.

Neither age nor sex nor duration of illness had any influence on the serological results. More than a quarter of both patients and control persons remembered tick bites. Controls, however, reported more frequently forest visits than multiple sclerosis patients, a fact which possibly has to be interpreted as being due to the physical impairment and immobility from which many multiple sclerosis patients suffer.

Thus, the following conclusions can be drawn: it seems to be very unlikely that the relapsing/remitting form of multiple sclerosis is associated with Borrelia burgdorferi. A few of those suffering from chronic progressive multiple sclerosis possibly might be associated with this agent as proposed by several authors; ;6810-1416 no significant correlation, however, could be found. The high prevalence of $\boldsymbol{B}$. burgdorferi antibodies in our series confirms previous reports of up to $20 \%$ prevalence rates in Tyrol $^{26}$ (further unpublished data). Since none of the healthy borrelia antibody positive controls reported any signs and symptoms suggestive of first or second stage Lyme borreliosis, latent infections with borreliae are very likely to occur. ${ }^{2528}$ Muhlemann and Wright showed in experimental murine borrelia infections that borreliae can remain dormant in the brain of mice for years. ${ }^{29}$ Whether this is also applicable to humans has yet to be proved but it might confirm the presented epidemiological observations.

This work was partially presented at the Congress: Lyme Borreliosis Update Europe, 2-4 June 1987, Baden, Austria.

\section{References}

1 Pachner AR, Steere AC. The triad of neurologic manifestations of Lyme disease: Meningitis, cranial neuritis and radiculoneuritis. Neurology 1985;35:47-53.

2 Pachner AR, Steere AC. CNS Manifestations of third stage Lyme disease. Zentralbl Bakteriol Hyg A 1986;263:301-6.

3 Ackermann R, Gollmer E, Rehse-Küpper B. Progressive Borrelien-Encephalomyelitis. Dtsch Med Wochenschr 1985; 110:1039-42.

4 Bendig JWA, Ogilvie D. Severe encephalopathy associated with Lyme disease. Lancet 1987;i:681-2.

5 Reik L, Smith L, Khan A, Nelson W. Demyelinating encephalopathy in Lyme disease. Neurology 1985;35:267-9.

6 Ackermann R, Rehse-Küpper B, Gollmer E. Progressive Borrelia Encephlomyelitis. Zentralbl Bakteriol Hyg A 1986;363: 297-300.

7 Klenk W, Heitmann R, Ackermann R. Rezidivierende ErythemaChronicum-Migrans-Krankheit des Nervensystems: Querschnittsmyelitis als Rückfall einer Meningopolyneuritis Garin-Bujadoux-Bannwarth. Akt Neurol 1985;12:20-3.

8 Baumhackl U, Kristofferitsch W, Sluga E, Stanek G. Neurological manifestation of Borrelia burgdorferi-infections: the enlarging clinical spectrum. Zentralbl Bakteriol Hyg A 1986; 263:334-6. 
9 Kohler J, Kasper J, Kern V, Thoden U, Rehse-Küpper B. Borrelia encephalomyelitis. Lancet 1986;i:35.

10 Kohlhepp W, Mertens HG, Oschmann P. Acute and chronic illness after tickbite Borrelia burgdorferi infections. Results of treatment. Zentralbl Bakteriol Hyg A 1986;263:365-71.

11 Pfister HW, Einhäupl KM, Wilske B, Preac-Mursic V. Bannwarth's Syndrome and the Enlarged Neurological Spectrum of Arthropod-borne Borreliosis. Zentralbl Bakteriol Hyg A 1986;263:343-7.

12 Steere AC, Bartenhagen NH, Craft JE, et al. Clinical Manifestations of Lyme Disease. Zentralbl Bakteriol Hyg A 1986;263:201-5.

13 Stiernstedt G, Sköldenberg B. Garde A, et al. Clinical Manifestations of Borrelia Infections of the Nervous System. Zentralbl Bakteriol Hyg A 1986;263:289-96.

14 Weder B, Wiedersheim P, Matter L, Steck A, Otto F. Chronic progressive neurological involvement in Borrelia burgdorferi infection. J Neurol 1987;234:40-3.

15 Fumarola D. Multiple sclerosis and Borrelia burgdorferi. Lancet 1986;il:575.

16 Klöter J, Adams I, Schabet M, Wiethölter H, Pfeiffer J. Borreliainduced meningoradiculitis - two different forms of the disease. Eur Neurol 1986;25:262-8.

17 Benoit P, Dournon E, Destee A, Warot P. Spirochetes and Lyme disease. Lancet 1986;ii: 1223

18 Rousseau JJ, Lust C, Zangerle PZ, Bigaignon G. Acute transverse myelitis as presenting neurological feature of Lyme disease. Lancet 1986;ii:1222-3.

19 Gay D, Dick G. Is multiple sclerosis caused by an oral spirochaete? Lancet 1986;ii:75-7.

20 Gay D, Dick G. Spirochaetes, Lyme disease, and multiple sclerosis. Lancet 1986;ii:685.

21 Kristoferitsch W, Steck AJ, Murray N, Stanek G, Lanschützer H. Oligoclonal Antibodies in CSF of Patients with meningopolyneuritis Garin-Bujadoux-Bannwarth: IgG Class, Light
Chain Type and Specificity. Zentralbl Bakteriol Hyg A 1986;263:307-13.

22 Poser CM, Paty CW, Scheinberg L. New diagnostic criteria for multiple sclerosis: guidelines for research protocols. Ann Neurol 1983;13:227-31.

23 Rose AS, Ellison GW, Myers LW, Tourtelotte NW. Criteria for the clinical diagnosis of multiple sclerosis. Neurology 1986;26:20-2.

24 Münchhoff P, Wilske B. Preac-Mursic V. Schierz G. Antibodies against Borrelia burgdorferi in Bavarian Forest Workers. Zentralbl Bakteriol Hyg A 1986;263:412-9.

25 Paul H, Gerth HJ, Ackermann R. Infectiousness for humans of ixodes ricinus containing borrelia burgdorferi. Zentralbl Bakteriol Hyg A 1986;263:473-6.

26 Schmutzhard E, Dierich MP, Gerstenbrand F, et al. Zur Epidemiologie der durch Zecken übertragenen neurologischen Krankheiten in Tirol. Neuropsychiatrie 1985;1:18-23.

27 Stanek G, Hirschl A, Kristoferitsch W. IFT and ELISA in der serologischen Diagnose der Lyme-Borreliose. Mitt Österr Ges Tropenmed. Parastologie 1986;8:1-6.

28 Schmutzhard E, Pohl P, Stanek G. Lyme borreliosis and multiple sclerosis. Lancet 1987;i:167-8.

29 Muhlemann MF, Wright DJM. Emerging pattern of Lyme disease in the United Kingdom and Irish Republic. Lancet 1987;i:260-2.

This survey was supported by the Austrian "Fonds zur Förderung der wissenschaftlichen Forschung", Project Number P6040 M.

The authors gratefully acknowledge the secretarial expertise of Miss Sigrid Permoser. 